Regina Helena Martins de Faria

Mestre e doutora em História pela

Universidade Federal de Pernambuco

(CFCH/UFPE - Recife/Brasil), e

professora no Departamento

de História e no Programa de

Pós-Graduação em História da

Universidade Federal do Maranhão

(CCH/UFMA - São Luis/Brasil)

e-mail: rhfaria@yahoo.com.br
COSTA, Yuri e GALVES, Marcelo Cheche.

O Epaminondas Americano: trajetórias de um advogado português na Província do Maranhão.

São Luís: Café \& Lápis / Editora UEMA, 2011. 241p.

\section{O Epaminondas Americano}

0 título do livro soa pomposo. A quem os autores chamam de Epaminondas Americano? Logo nas primeiras páginas vimos não se tratar de um pseudônimo, mas de um dos heterônimos assumidos por um português, 0 bacharel em Direito Manoel Paixão dos Santos Zacheo, em vários escritos que fez publicar, nos decênios de 1820 e 1830, manifestando seus posicionamentos nos debates ocorridos no Maranhão, após a Revolução do Porto (ou Vintismo) e nos primeiros tempos da constituição do Estado brasileiro.

Esse advogado é um personagem intrigante. Na Universidade de Coimbra, onde estudou, seu nome consta como Manoel Paixão dos Santos, mas o sobrenome Zacheo ou Zaqueu já estava incorporado nos documentos que atestam sua chegada ao Maranhão em 1810, e permaneceu nos registros posteriores. Os autores do livro levantam a hipótese de ele ter querido associar sua imagem à conotação hebraico-religiosa do termo "zacheo", que significa "puro". Quanto ao heterônimo Epaminondas, supõem ser uma possivel "referência ao general tebano, que liderou a vitória contra as tropas espartanas na batalha de Leuctras (371 a. C.)". E explicam:

\footnotetext{
Vencedor de lutas sangrentas - que Ihe custaram a vida -, Epaminondas também ficara conhecido como homem de larga cultura e pelo princípio de jamais mentir. Coragem, conhecimento e sinceridade, aliadas à "pureza" pregressa, parecem compor a base da personalidade assumida por Manoel Paixão dos Santos - 0 Zacheo-Epaminondas -, forma de legitimar uma imagem de si e desqualificar a de seus oponentes (p.27).
}

A autoimagem favorável aparece em outro heterônimo que usou em duas publicações - o Arguelles da província. Para este, os autores levantam a hipótese de uma "provável alusão a Augustin de Arguelles Alvarez, deputado espanhol às Cortes de Cadiz, instância na qual ficou conhecido como o 'divino', dada a qualidade de sua oratória" (p.28).

No Maranhão, Zacheo não tardou a se integrar em várias redes de sociabilidade. Quando seus escritos vêm a público, dez anos após sua chegada, está casado com uma moça da terra, é advogado do Tribunal da Relação do Maranhão, juiz demarcante dos julgados do Mearim e das vilas de Viana, Tutóia e Icatu, além de declarar-se dono de fazendas e escravos em Rosário e Alcântara. Atuava, portanto, na capital da Província, a cidade de São Luís, situada numa ilha costeira, e em localidades do continente.

Em abril de 1821, foi um dos oito cidadãos que votou contra o prolongamento da administração de Bernardo da Silveira Pinto da Fonseca - o último governador da província do Maranhão antes do Vintismo - e defendeu a instalação de uma junta governativa. Em janeiro daquele ano, uma representação de sua autoria havia sido lida nas Cortes portuguesas. Outras foram apresentadas nos meses seguintes. Denunciava tramoias do 
governador e fazia sugestões para o trabalho dos constituintes. A oposição a Pinto da Fonseca levou-o a refugiar -se na vizinha província do Grão-Pará e Rio Negro, para escapar da prisão que este Ihe decretara. Retornou ao Maranhão no ano seguinte.

No início de 1823, como essa província permanecesse fiel a D. João $\mathrm{VI}$, Zacheo foi um dos deputados eleitos para a segunda legislatura das cortes portuguesas. Viajou para Lisboa, mas não assumiu o cargo, pois encontrou as Cortes dissolvidas e o antigo regime restaurado. Permaneceu alguns meses em Portugal. Em $1^{\circ}$ de janeiro de 1824, a bordo da escuna que o trazia para o Brasil, participou de um ato solene de juramento à independência do novo país. Retornando ao Maranhão, retomou as atividades políticas. Continuou com os escritos inflamados; os opositores acusavam-no de ter "má língua". Apoiou o conturbado governo de Miguel Ignácio dos Santos Freire e Bruce, o primeiro presidente nomeado pela Coroa brasileira para a província. Criticou D. Pedro I, mas dedicou-Ihe um trabalho de quase cem páginas, para subsidiar os Códigos Civil e Criminal que o Brasil precisava elaborar. Elegeu-se deputado para o Conselho Geral da Província e integrou o Conselho Presidial (ou de Governo).

A singular personalidade de Zacheo, sua trajetória de vida e o teor dos escritos que publicou o tornam um objeto de estudo privilegiado. Yuri Costa e Marcelo Cheche Galves, professores da Universidade Estadual do Maranhão, foram extremamente felizes ao escolhê-lo, especialmente porque puderam potencializar o capital cultural acumulado em outras vivências intelectuais. Galves defendeu, em 2010, na Universidade Federal Fluminense, a tese de doutorado em História, intitulada "Ao público sincero e imparcial": imprensa e independência do Maranhão (1821-1826). E Costa fundamenta-se na dupla formação de historiador e bacharel em Direito.

Os autores foram felizes também na maneira como apresentam os resultados do estudo realizado. Organizaram o livro 0 Epaminondas Americano em duas partes. Na Parte I - Advogado, Proprietário e Político -, estruturada em quatro capítulos, a proposta é fazer um "recorte biográfico", entremeado pelas tensões de "ação individual" e "contexto" (p.19). Na Parte II - Documento, nos presenteiam com a reprodução facsimilar de um exemplar existente na Fundação Biblioteca Nacional - Brasil da publicação, que certamente é a mais importante entre as lançadas pelo advogado: Projectos do Novo Código Civil e Criminal no Império do Brasil, oferecidos ao Senhor D. Pedro I, Imperador Constitucional seu Protector e Defensor Perpétuo e ao Soberano Congresso Nacional e Legislador.

$\mathrm{Na}$ Introdução, avisam aos leitores que tratarão apenas da atuação pública de Zacheo no Maranhão, principalmente dos dois decênios em que publicou seus trabalhos. Mas fazem bem mais que isso. No primeiro capítulo da Parte I, Um publicista irrequieto, traçam uma narrativa biográfica que informa sobre a família, o local de nascimento e 0 período em que o biografado esteve em Coimbra; especulam acerca dos significados dos nomes que adotou; delineiam suas múltiplas inserções na vida política da Província e contextualizam as polêmicas em que ele se envolveu e que geraram seus escritos, além de outros aspectos de sua vida pública.

No segundo capítulo, $O$ bacharel e as leis, enveredam pela cultura jurídica luso-brasileira da época. A intenção é situar a produção de Zacheo nos dois processos em que ele foi partícipe: a "modernização da cultura 
jurídica em Portugal" e a "construção organizacional e legislativa do Brasil independente". É também buscar entender as "práticas e as representações que se originam no (ou perpassam o) campo jurídico e dão sentido à atuação de profissionais do Direito (p.43)", em Portugal e no Brasil.

Expõem o teor da reforma acadêmica implantada na Universidade de Coimbra, a partir da década de 1770 , e as principais mudanças que a reforma trouxe nas concepções e nas práticas jurídicas na metrópole e em sua possessão na América. Adotam a periodização da História do Direito Português, elaborada por Nuno J. Espinosa Gomes da Silva, que Ihes permite situar nosso advogado na transição do período de influência iluminista (que vai da metade do Setecentos à Revolução de 1820) para o período de influência liberal e individualista (dessa revolução liberal ao início do Novecentos). Mostram que Zacheo conviveu com a crítica ao Direito românico e à tradição medieval canônica, com a valorização do Direito nacional (o então chamado Direito pátrio), a formulação do Direito natural moderno e as concepções ilustradas sobre o Estado e o indivíduo. Veem em sua obra diferentes concepções teóricas, fruto da formação acadêmica e das experiências vividas na América Portuguesa. Era, por exemplo, um entusiástico defensor do constitucionalismo, julgando-o perfeitamente conciliável com a monarquia e a escravidão. Entendia que as "boas leis" eram fruto do intelecto humano, e não deveriam servir apenas para nortear as ações dos governantes, mas ser um meio de viabilizar "a distribuição da 'felicidade' no corpo social" (p.41). Além disso, seriam boas as leis que tivessem redação clara e simples, de modo a permitir compreensão correta e eficaz execução. E Zacheo procurava seguir esses princípios nas sugestões que enviou a legisladores e governantes.

Os autores entendem que ele, informado e formado nestes e por estes debates intelectuais e jogos políticos, procurou ser um cidadão participante, como jurista, publicista e político, tanto em relação ao Estado português quanto ao Estado brasileiro que via nascer. E historiam suas múltiplas atuações e analisam-Ihe as publicações, dialogando com a literatura que trata das ideias presentes nos projetos políticos em discussão no Brasil nas primeiras décadas do Oitocentos.

No terceiro capítulo, Da justiça ou da falta dela, a análise dos escritos e da atuação de Zacheo volta-se mais para as denúncias que ele fez a homens públicos da província do Maranhão. Foi um áspero crítico dos desmandos das autoridades judiciais, acusando-as de negligência, abuso de poder e conluio com os governantes. Fundamentava as acusações com casos vivenciados como advogado no Tribunal da Relação dessa província e chegou a sugerir a extinção não só deste, como dos demais Tribunais da Relação, justificando que desembargadores, corregedores e juizes tinham práticas espúrias.

Mas sua ira não se voltava apenas para os togados. Era vigilante em relação aos jogos políticos e às ações dos ocupantes dos altos cargos do Executivo. Abordando essa faceta do biografado, os autores entram nos meandros da história da imprensa no Maranhão. Como a primeira tipografia da província foi instalada na administração de Pinto da Fonseca e sob os auspícios do governo, por ser desafeto dessa autoridade e crítico de outras pessoas gradas na política local, Zacheo precisou publicar a maior parte de seus primeiros escritos em outros lugares.

Esse capítulo analisa também as posições do advogado acerca do sistema escravista, criando a ocasião para Costa e Galves entrarem nos 
debates que tratam da história das ideias sobre a escravidão. Mostram que Zacheo, como muitos outros declarados adeptos do liberalismo àquela época, não via qualquer possibilidade de "grandeza" e "opulência" para o Brasil sem o recurso do braço escravo. A familiaridade dele com a obra de Antonil é notada não apenas na utilização desses dois termos; revela-se ainda na metáfora consagrada pelo padre de serem os escravos os "braços" e "pernas" de quem almejasse ser proprietário por essas terras. Assim, não propunha o fim da escravidão nem do tráfico humano transatlântico. Julgava que o constitucionalismo monárquico não era afetado pela existência de escravos, pois estes eram naturalmente inclinados ao cativeiro. Aliava este argumento - baseado na concepção milenar da "servidão natural", que subordina alguns povos e/ou pessoas - a outros com base religiosa e racionalista. Desse modo, a inferioridade e a preguiça que atribue serem inatas aos "negros" e "indios" não resultariam apenas da vontade divina. Deus criara todos com o livre arbítrio de "obrar ou não obrar". Foram eles que decidiram não trabalhar e permanecer na ociosidade e na libertinagem (p.98). No "estado natural" em que se encontravam, tornavam-se "cidadãos impossíveis".

0 quarto capitulo da Parte I, A adaptação aos novos tempos: o Zacheo "brasileiro", aborda a inserção dele na política, após o retorno de Portugal, quando o Maranhão já fazia parte oficialmente do Império do Brasil. Os autores especulam sobre as razões que o teriam levado a optar pela volta.

Em tal decisão, talvez tenham pesado, de um lado, a guinada absolutista da política portuguesa; e de outro, a perspectiva constitucional brasileira, corporificada pela reunião de uma Assembleia Constituinte. Porém, não é possivel ignorar outras razões, como os vínculos familiares que criou na província, o patrimônio que acumulou e a legitimidade que conquistou, como fatores de seu regresso (p102).

Seguindo indícios encontrados em escritos de Zacheo e de outros publicistas da época, consideram que ele integrava e (ou) apoiava o grupo político que subiu ao poder na Província, com o presidente Miguel Ignácio dos Santos Freire e Bruce (1824-1825), após a adesão à Independência. 0 curto governo de Bruce foi bastante tumultuado. Por mais de uma vez os opositores tentaram derrubá-lo; houve repetidas sublevações da "tropa" e do "povo"; além de ter sido acusado de apoiar a Confederação do Equador. Acusação que recaiu também sobre nosso advogado, que conta em um de seus escritos ter sido preso em São Luís, no ano de 1824, possivelmente num dos motins contra esse governo.

Nesse capítulo o foco é no Zacheo que jurou a independência do Brasil e participou das tramas políticas em momentos de fortes manifestações de antilusitanismo na Província, quando a expulsão de portugueses constava da pauta das reivindicações dos movimentos populares. Inclusive, ele integrava o Conselho Presidial da Província, quando houve a Setembrada (em 1831) e participou das deliberações sobre as principais exigências dos rebelados: "expulsão dos postos militares dos 'brasileiros por Constituição'; expulsão dos 'brasileiros adotivos' de todos os empregos civis, de Fazenda e Justiça [...]" (p.111).

Por fim, à guisa de introdução da Parte II, no texto Os Projetos de Zacheo e seu tempo, os autores fazem ainda uma análise do documento reproduzido, cotejando-o com outros projetos que lhe foram contemporâneos, à luz da discussão historiográfica sobre os assuntos abordados. 
0 Epaminondas Americano insere-se, portanto, na profícua produção acerca do processo de independência, da construção do Estado e formação da nação brasileira. Embora essas temáticas possuam lugar cativo nos clássicos da História do Brasil, nas últimas décadas foram retomadas com renovado interesse, devido ao fortalecimento da "nova história política" e à diversificação das abordagens no campo histórico. 0 vigor dos debates pode ser visualizado nos balanços historiográficos sobre a produção clássica e a recente, bem como na grande quantidade de novos títulos publicados, entre os quais este livro vem ocupar importante lugar. 